\title{
Analysis on the Energy-saving Optimization of Thermal Energy and Powered Cogeneration System
}

\author{
Yueqiu Sun \\ Bohai Ship-building Vocational College, Huludao, Liaoning, 125105
}

Keywords: thermal energy, powered cogeneration system

\begin{abstract}
The application of thermal energy cogeneration system in industrial production is very common and it is one of the important basic kinetic energy for industrial development. In today's social environment, the proposal of sustainable development makes the thermal energy and power cogeneration system move toward the direction of energy conservation and optimization. Based on the purpose of sustainable development, this paper analyzes the current thermal energy and power cogeneration system, explains its direction towards energy conservation and necessity, based on the characteristics of thermal power cogeneration system, and puts forward several energy-saving optimization methods, and the effect and feasibility of the implementation of a simple introduction, in order to provide a suggestion for energy-saving optimization of thermal power cogeneration system.
\end{abstract}

\section{Introduction}

With the rapid economic development, the energy consumption of various industries and industries continues to increase, and the world is facing an energy crisis. Therefore, energy conservation and emission reduction have become an important measure for energy conservation in the country. The thermal energy system converts thermal energy into mechanical energy. Its working state belongs to the power cycle, which includes obtaining heat from a high-temperature heat source, starting from a high-temperature and high-pressure state, and evacuating the system's waste heat. At present, the high-temperature heat source of the thermal power system is mostly derived from the combustion of fossil fuels, and the chemical energy is converted into heat energy by combustion. Since most modern thermal power systems use non-renewable fossil fuels as their energy source, improving the energy efficiency of thermal energy systems has important implications for alleviating energy crisis, reducing pollution, protecting the environment, and improving the efficiency of enterprises. In addition, the thermal energy system includes the conversion of chemical energy into thermal energy, thermal energy into mechanical energy, and waste heat discharge into the environment. Its working process includes many irreversible steps such as combustion, temperature difference heat transfer, and flow resistance. There are potential energy savings in these links. .

\section{Related theory content of cogeneration system}

In the theory of thermal energy cogeneration system, the core content of its research is ladder-type energy utilization and chemistry. In these two aspects, it is mainly to control the integration of CO2, which is also to achieve the thermal energy cogeneration system. The key foundation.

In thermodynamics research, the main theoretical basis of the traditional thermodynamic circulation system is Carnot's quantification. The theory's point of view is to use the method of reducing fuel taste to heat taste. However, in this theory, the use of chemical energy content is not used, so there may be some limitations in the specific application. In order to break this situation, some experts used the traditional theoretical content as a basis to establish a closer relationship between the three aspects of free energy taste, fuel chemical energy taste and heat energy taste, and through this contact method, the An explanation of the integration concept that can be converted to 
co-production is provided. A large number of experiments have proved that there are certain mutual couplings between the energy conversion and the conversion of the components in the application of the theory. In the entire contact system, the integration between the chemical side and the dynamic side is the key to integration. Content is the core theory when it comes to using energy ladders.

In the current thermal power and power cogeneration system, to achieve the goal of energy conservation and optimization, appropriate improvements should be made to the content of some traditional concepts. In terms of production, there are working ideas for pollution control first, and the contents of $\mathrm{CO} 2$ control integration and energy conversion and utilization are mainly directed at this idea. In the current thermal system, the tail removal of the process is the main method of controlling pollution, but this method will cause some pollution in the early period, and the management of the later period is lacking, so we must solve this problem. Problems can be solved by using $\mathrm{CO} 2$ control integration and energy conversion technologies. The principle of this kind of work is mainly to use the steps between chemical energy and CO2 to reduce the separation of energy consumption and content, so as to improve the utilization of energy, and to achieve the purpose of reducing $\mathrm{CO} 2$ emissions. Using this method, we can fundamentally eliminate the current work content of the first pollution control, can also reduce the volatilization of greenhouse gases, appropriate recovery of some $\mathrm{CO} 2$ gas, and combine the content of separation technology to separate clean fuel hydrogen. come out. In the control of the proportion of synthetic gas, this method is also more scientific and rational, and it can ensure that the use of chemical synthesis is more optimized and $\mathrm{CO} 2$ emissions are reduced, laying a solid foundation for the development of CO2 integration methods.

\section{Boiler waste water preheating recycling technology}

In terms of sewage discharge, it can be mainly divided into two main ways: regular discharge and continuous discharge. In most boiler operations, the use of a single-stage sewerage system to treat sewage is common. This type of effluent can be used to discharge sewage directly during regular effluent discharges. In the case of continuous effluent, After the expansion of the sewage expansion vessel, the secondary steam is first recovered in appropriate amounts, and then the heat-carrying sewage is discharged. However, the above two kinds of sewage discharge measures all have some problems in the loss of heat and water resources, and they will cause no small pollution to the environment. Therefore, in order to achieve the purpose of energy conservation and optimization, the hot water to be discharged may be used rationally during the process of boiler sewage discharge. It may be possible to install a corresponding recovery device behind the boiler room to discharge the waste heat waste water. For the necessary recovery of the heat of the sewage, a septic cooler can be installed on the basis of the skimmer so that further expansion can be carried out for the expanded water and the utilization efficiency of the boiler energy can be improved to reach the final level. Energy-saving purpose.

\section{Reformation Technology of Steam Condensate Recovery System}

In the actual energy-saving optimization work, the main content of the energy-saving reform technology for the steam system is to use the waste heat generated in the process of condensing steam to replace the contents of the low-pressure steam. With this technique, it is possible to reduce the loss of low-pressure steam capacity. In the recovery of condensate, optimization of the condensate pipe network design, as well as dispersion front pressure recovery technology, can not only ensure the condensate pipe network operation has a certain degree of efficiency, but also can ensure that the heat exchanger can be Work normally. The recovery of condensed water can be mainly divided into two types: (1) Pressurized water return, this method is mainly to use steam-driven condensate pump to pressurize the condensed water, which is suitable for those with lower temperature. , The lower residual water pressure, and the more dispersed state of condensate, the system is relatively stable operation, and has a higher explosion-proof performance, lower 
maintenance required later; (2) back pressure backwater, this The main method is to use the back pressure of the trap as the main power, and then transfer the condensed water and flash steam to the designated water return point. The applicable objects are mainly pressurized equipment with high pressure of pressurized hot steam and backwater back pressure not too high. The use of back pressure and water return not only improves the value of condensate, but also makes full use of flash steam, but when using this technology, it is necessary to effectively guarantee the performance of the trap.

When industrial boilers are used for exhausting smoke, temperatures as high as several hundred degrees Celsius can cause significant heat loss. To achieve the goal of energy conservation optimization, reasonable use must be made of the contents of this section. In the process of boiler operation, some special energy savers can be used to apply the waste heat of this part of the exhaust gas to the thermal dynamic cycle; or at the end of the boiler, through the installation of low-pressure economizer, in the heat Between the dynamic systems, a suitable water level is connected, so that the waste heat generated by the boiler exhaust smoke can be fully utilized, which can not only help the company obtain good economic benefits, but also achieve the purpose of energy conservation. In the boiler smoke recovery work, there are mainly two methods: (1) Preheat the workpiece. During this work process, due to the large area required for heat exchange, it may be affected by the site during the implementation. (2) Preheating the air is mainly performed by arranging it on a heating furnace to intensify its combustion conditions, and its energy-saving effect is significant. In the operation of the gas boiler, the flue gas residual heat condensing and recovering device may also be used to use the lower temperature water to cool the flue gas, thereby achieving the purpose of recovering heat by condensation and improving the thermal efficiency of the boiler.

\section{Energy Saving Technology of Chemical Supplementary Water System}

When using the technology of chemical make-up water system, some related application conditions should be standardized. For example, in civil boilers, the condenser and deaerator need to be entered before entering the thermodynamic system for a pumping-type unit. In this way, a chemical supplemental water system can have a good oxygen removal system. In addition, in order to ensure the vacuum quality of the steam turbine and improve the economy of its heat recovery, it is also possible to install corresponding devices in the incoming condenser to help the chemical make up water, which can be in the state of water mist. Into the condenser, in order to produce a high level of steam, steam turbine steam quality, as well as the economic benefits of heat recovery. In some current thermal energy applications, water spray is usually used to cool the heat so that the high heat energy can be reduced to low heat energy and the hot steam can be reduced to micro over steam to allow the user to use it. This method has produced a certain amount of waste, which is not conducive to the purpose of energy conservation and emission reduction. When using superheated steam heating, the main task is to add superheated heat to the heat system through a special device to allow it to work in the steam turbine and complete the heat. Conversion and utilization. Reasonable use of superheat can improve economic efficiency, and can also improve the cycle thermal efficiency of the condenser unit to achieve energy-saving and optimized use. When using the above-mentioned energy-saving technologies, the purpose of the transformation can be achieved by adding corresponding device contents to the original system, and through comprehensive comparison, it is found that the required transformation costs are also more economical, but through this transformation method, The optimization effect made by the system is enormous. After all, it can protect the environment. At the same time, it is also very significant in the performance of energy-saving optimization. Therefore, relevant personnel should increase research efforts and carry out energy-saving design possibilities. Dig deeper.

\section{Conclusion}

Thermal energy and power cogeneration system is an important part of China's industrial industry. It plays a very important role in the development of industry. Under the current demand of 
environmental resources, the development of thermal energy and power cogeneration systems toward energy conservation is an inevitable development trend. Effectively increasing the energy conversion efficiency has also become an important issue that current researchers need to solve. In view of the use of this thermal power cogeneration system, the specific energy-saving optimization design should be multifaceted and take different approaches. The proper design of design means can ultimately improve its energy-saving effect. It is hoped that some of the specific measures proposed in this paper will help improve the energy-saving level of future thermal power cogeneration systems.

\section{References}

[1] Tian Yuezong. Analysis and discussion on energy-saving optimization of thermal energy cogeneration system [J]. Heilongjiang Science \& Technology Information, 2016(23): 20.

[2] Wu Gang. Analytical energy-saving reform of thermal energy cogeneration system [J]. Jiangsu Science and Technology Information, 2014(20): 35-36.

[3] Lin Jianggang. Energy-saving Optimization Analysis of Thermal Energy and Power Cogeneration System [J]. Scientific Innovation and Application, 2014(19): 130.

[4] Lin Jianggang. Energy-saving Optimization Analysis of Thermal Energy Cogeneration System [J]. Science and Technology Innovation and Application, 2014(19).

[5] Xu Yunfeng. Thermal Energy Cogeneration and Its System Optimization Analysis [J]. Management and Technology of SMEs, Science and Technology Xun Issue, 2013 (18). 